\title{
Prenatal Screening Syphilis: Is Universal Screening Necessary in Saudi Arabia?
}

\author{
Sharifa A. Al-Sibiani, MB, CHB, CABOG \\ Department of Obstetrics and Gynecology, \\ Faculty of Medicine, King Abdulaziz University Hospital \\ Jeddah, Saudi Arabia \\ sharisibiani@yahoo.com
}

\begin{abstract}
To study the seroprevalence of syphilis among pregnant women; attending their first prenatal examination, and the value of routine prenatal screening for syphilis at the Antenatal Clinic of King Abdulaziz University Hospital, Jeddah, Saudi Arabia. A retrospective analysis of the routine prenatal tests results of women attending for their first antenatal booking visits over a period of 3 years, between January $1^{\text {st }}, 2004$ and December $31^{\text {st }}$, 2007. For all women, the results of the routine prenatal venereal disease; research laboratory and rapid plasma reagin tests were reviewed and correlated with data on age, nationality, gravidity, parity and number of abortions. The sample study was comprised of 8,989 women. There were 8,987 successful tests; only two cases $(0.02 \%)$ were seropositive for the syphilis antibody (positive VDRL/RPR). Confirmatory treponemal tests (Treponema pallidum hemagglutination assay) were negative. Therefore, prevalence of syphilis at first prenatal visit of the subjects in this study was zero. Low prevalence of syphilis in prenatal and obstetric population had been reported in the few research studies in Saudi Arabia. The new findings of this present study increase the importance of a nation-wide survey to guide the revision of practice at a national scale in Saudi Arabia.
\end{abstract}

Keywords: Syphilis, Prenatal screening, Saudi Arabia.

\section{Introduction}

Prenatal care aims to preserve the health of the mother and fetus, preventatively screening for indices of illness or pregnancy-related

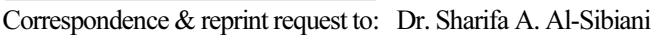

P.O. Box 122413, Jeddah 21332, Saudi Arabia

Accepted for publication: 15 December 2008. Received: 15 September 2008.
} 
complications. Routine prenatal serological screening tests can detect some potentially serious infectious diseases such as; syphilis, Hepatitis B, and susceptibility to infections such as rubella, allowing timely intervention to prevent adverse pregnancy outcomes.

Syphilis is a sexually transmitted disease that constitutes a public health problem in many parts of the world, including developed countries $^{[1]}$. The presence of this disease in pregnant women can adversely affect pregnancy outcome. Although, there is considerable variation in the way the adverse outcomes of pregnancies of women infected with syphilis are reported. It is generally accepted that they include spontaneous abortion, prenatal death, low birth weight (including prematurity), and neonatal infection with syphilis. Several models have been proposed to estimate adverse pregnancy outcomes in women infected with syphilis, with resulting estimates ranging from $50 \%$ to $80 \%{ }^{[2-5]}$. Transmission occurs more commonly in the last two trimesters, but the spirochete can cross the placenta at any time during pregnancy ${ }^{[6]}$. Fetal death and morbidity due to congenital syphilis are preventable if the infected mother is identified and treated appropriately by the middle of the second trimester.

Most pregnant women with syphilis are asymptomatic and the disease can only be identified through screening programs. The prevalence of syphilis seroreactivity among pregnant women varies considerably among the world's populations, from as low as $0.02 \%$ to high as $12.1 \%^{[7]}$. Despite that prenatal syphilis screening has been recommended for all pregnant women at least once at their first antenatal visits.

Non-treponemal tests such as rapid plasma reagin (RPR) and venereal disease research test (VDRL) are helpful indicators of infection, are cheaper, and are simpler to perform than treponemal tests. The sensitivity of these tests increases from primary to secondary syphilis, while their specificity is generally high in the absence of an underlying chronic disease ${ }^{[8]}$. RPR and VDRL can also give false-positive results. Ideally, positive non-treponemal tests should be confirmed by a treponemal test, such as the Treponema Pallidum Hemagglutination Assay (TPHA) or the Fluorescent Treponemal Antibody Absorption (FTA-ABS) test. 
Treponemal tests have higher sensitivity and specificity, but do not correlate with disease activity; are difficult and costly to conduct, plus they are not recommended for primary health care facilities ${ }^{[8-10]}$. Therefore, when if resources are limited in communities with known high prevalence of syphilis, treatment of all people testing seropositive with RPR may be justified ${ }^{[11]}$. In a population with low rate of syphilis, the value of routine testing with RPR/VDRL should be reconsidered.

Data on syphilis in Saudi Arabia is limited, but in general it is inline with the notion of low prevalence. In a non-obstetric population, one local study by Madani ${ }^{12]}$ showed that $8.7 \%$ of reported sexually transmitted infections (STIs) to Ministry of Health were syphilitic. Another study by Hamdi et $a l .{ }^{[13]}$ found the relative frequencies for syphilis among domestic expatriate workers (DEWs) screened for preemployment is $23.8 \%$, more frequent among Indonesian and the Philippines nationals.

Also, local studies in an obstetric population reported a $0.03-0.85 \%$ prevalence, again supporting a low prevalence $e^{[7,12,14-16]}$.

The aim of this study is reflected on the value of doing a routine prenatal syphilis screening among our population at King Abdulaziz University Hospital by determining the prevalence of positive nontreponemal tests (RPR/VDRL) and positive confirmatory treponemal tests (TPHA).

\section{Materials and Methods}

This is a retrospective hospital-based study (prevalence study) in which the results of the routine prenatal VDRL and RPR tests of 9,898 women attending the prenatal clinic between January 1, 2004 and December 31, 2007 were reviewed. The results were correlated with the patients' age, nationality, gravidity, parity, and number of abortions. The study was undertaken at King Abdulaziz University Hospital (KAUH) in Jeddah, which is the main teaching hospital at the Western region of Saudi Arabia. The hospital provides tertiary medical care and performing 3,500-4,000 deliveries per year.

Data were entered in a computer and double-checked before analysis by Statistical Package for the Social Sciences (SPSS), Version 16 for Windows. The mean, standard deviation and percentage were calculated. 


\section{Results}

The recorded age range was 15 to 48 -years-old (mean $=27.53$ years; confidence interval of mean, $\mathrm{CI}=27.40-27.66$ ) (Fig. 1). Parity ranged from 0 to $14($ mean $=2.06 ; \mathrm{CI}=2.01-2.10)$, gravidity ranged from 1 to 17 (mean $=3.51 ; \mathrm{CI}=3.46-3.56)$ and history of abortions ranged from 0 11 (mean $=0.48 ; \mathrm{CI}=0.46-0.5)$. In the sample of 8,989 pregnant women, the results of two syphilis tests were lost. Seropositivity for the syphilis antibody (positive VDRL/RPR) was found in only two cases $(0.02 \%)$, and confirmatory TPHA tests were negative in both cases. Therefore, prevalence of syphilis at first prenatal visit in this study group is zero.

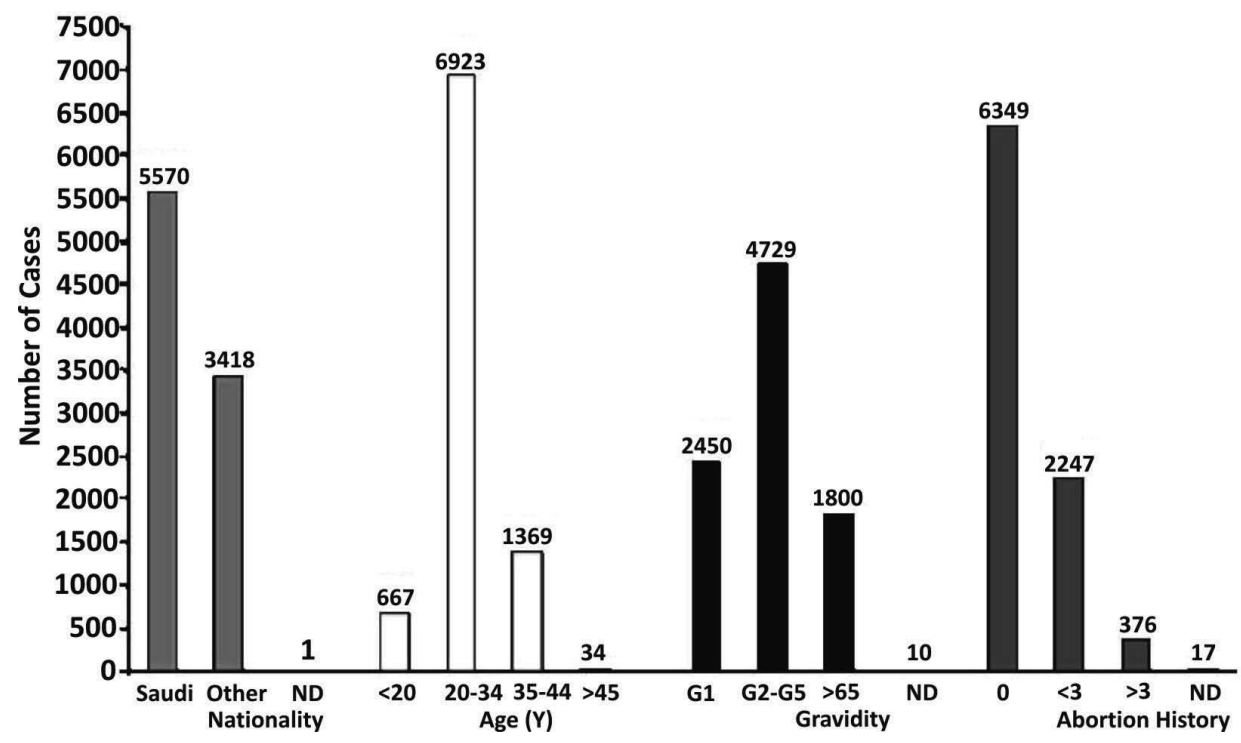

Fig. 1. Demographic characteristics of the sample.

\section{Discussion}

WHO (World Health Organization) recommended syphilis prenatal screening for all pregnant women at the first prenatal visit and early in the third trimester ${ }^{[17]}$. Furthermore, the United States Centers for Disease Control and Prevention (CDC) also recommends that all women should be serologically screened in early pregnancy, with further testing at 28 weeks of gestation, and at delivery in populations with a high prevalence of syphilis ${ }^{[18]}$. 
The prevailing practice in Saudi Arabia directs that all pregnant women should be screened for syphilis with a nontreponemal test (RPR or VDRL) at the first prenatal visit. Women with positive screening results are further tested with specific anti-treponemal antibody tests (TPHA or FTA-ABS).

In the present study there was no positive case of syphilis, indicating an extremely low prevalence rate of syphilis among the studied population. Considering that KAUH serve a mixture of social classes of population, one could state that the prevalence of syphilis among our local population is extremely low. Similar findings has previously been reported by Hossain $(1988)^{[15]}$ and Zimmo et al. $(2000)^{[16]}$ who have respectively reported a rate of $0.85 \%$ and $0.7 \%$ of syphilis among prenatal women. In Austria, Kiss et al. conducted a retrospective analysis of syphilis using a total of 34,312 sera obtained from women at delivery in the University of Vienna ${ }^{[19]}$. They concluded that universal syphilis screening might no longer be economically justified, and screening foci should shift to regions with a high seroprevalence of syphilis. Their recommendations seem to be appropriate when the results of studies from some African countries are examined where a prevalence of syphilis ranges from $3 \%$ to $18 \%$ were reported ${ }^{[18]}$.

Antenatal screening constitutes major health intervention that consumes considerable health resources, both financial and human ones. In these respects, universal recommendations for "best practice" are unlikely to be the appropriate approach for cost effective health care. Each population should determine its own specific potential health hazards; both on the mother and the baby, and accordingly plan of its prenatal care model.

In the Saudi population, few studies including the results of the present one, confirm the very low prevalence of rate of syphilis among pregnant women in Saudi Arabia. Based on the current and previous studies, it can be concluded that there are some trends towards a national low incidence of syphilis in obstetric population in Saudi Arabia ${ }^{[7,14-16]}$. This study is generally confirming a trend of low prevalence of syphilis in Saudi Arabia. Hamdi and Ibrahim had shown higher prevalence in the Indonesian and Philippine national residents subset of Saudi Arabian non-obstetric population ${ }^{[13]}$. In conclusion, findings might suggest the presence of low prevalence of syphilis in obstetric Saudi population. A 
confirmatory national surveillance would be of benefit to determine actual prevalence of syphilis in obstetric population. Nations with low prevalence of syphilis had changed their national syphilis screening policies. These changes might help in saving the cost of national antenatal syphilis screening.

In this present study, not a single case was found. Although, the study population was not representing the complete Saudi Arabian obstetric population but it is strongly demanding a nation-wide survey. This suggested survey should consider factors like nationality, origin, social style and past obstetric history. Therefore, the necessity to implement a nation-wide survey to assess the need for the continuation of universal prenatal syphilis screening; with regards to its potential benefits, cost effectiveness in Saudi Arabia or at least, a selective screening for specific population with higher risk of contracting syphilis in the Kingdom of Saudi Arabia.

\section{References}

[1] Nakashima AK, Rolfs RT, Flock ML, Kilmarx P, Greenspan JR, Epidemiology of syphilis in the United States 1941-1993, Sex Transm Dis, 1996; 23(1): 16-23.

[2] Saloojee H, Velaphi S, Goga Y, Afadapa N, Steen R, Lincetto O, The prevention and management of congenital syphilis: an overview and recommendations, Bull World Health Organ, 2004; 82(6): 424-430.

[3] Hira SK, Bhat GJ, Chikamata DM, Nkowane B, Tembo G, Perine PL, Meheus A, Syphilis intervention in pregnancy: Zambian demonstration project, Genitourin Med, 1990; 66(3): 159-164.

[4] Schulz KF, Cates W Jr, O'Mara PR, Pregnancy loss, infant death, and suffering: legacy of syphilis and gonorrhoea in Africa, Genitourin Med, 1987; 63(5): 320-325.

[5] Watson-Jones D, Gumodoka B, Weiss H, Changalucha J, Todd J, Mugeye K, Buvé A, Kanga Z, Ndeki L, Rusizoka M, Ross D, Marealle J, Balira R, Mabey D, Hayes R, Syphilis in pregnancy in Tanzania. II. The effectiveness of antenatal syphilis screening and single-dose benzathine penicillin treatment for the prevention of adverse pregnancy outcomes, J Infect Dis, 2002; 186(7): 948-957.

[6] Berman SM, Maternal syphilis: pathophysiology and treatment, Bull World Health Organ, 2004; 82(6): 433-438.

[7] Lumbiganon P, Piaggio G, Villar J, Pinol A, Bakketeig L, Bergsjo P, Al-Mazrou Y, Ba'aqeel H, Belizán JM, Farnot U, Carroli G, Berendes H; WHO Antenatal Care Trial Research Group, The epidemiology of syphilis in pregnancy, Int J STD AIDS, 2002; 13(7): 486-494.

[8] US Preventive Services Task Force, Counseling to prevent HIV infection and other sexually transmitted diseases: The Guide to Clinical Preventive Services, 2nd ed. Rockville, MD: Agency for Healthcare Research and Quality, 1996: 723-737.

[9] Augenbraun M, Rolfs R, Johnson R, Joesoef R, Pope V, Treponemal specific tests for the serodiagnosis of syphilis. Syphilis and HIV Study Group, Sex Transm Dis, 1998; 25(10): 549-552. 
[10] Terris-Prestholt F, Watson-Jones D, Mugeye K, Kumaranayake L, Ndeki L, Weiss H, Changalucha J, Todd J, Lisekie F, Gumodoka B, Mabey D, Hayes R, Is antenatal syphilis screening still cost effective in sub-Saharan Africa? Sex Transm Infect, 2003; 79(5): 375-381.

[11] Peeling RW, Ye H, Diagnostic tools for preventing and managing maternal and congenital syphilis: an overview, Bull World Health Organ, 2004; 82(6): 439-446.

[12] Madani TA, Sexually transmitted infections in Saudi Arabia, BMC Infect Dis, 2006; 6: 3.

[13] Hamdi SA, Ibrahim MA, Sexually transmitted diseases in domestic expatriate workers in Jeddah, Saudi Arabia, Ann Saudi Med, 1997; 17(1): 29-31.

[14] Shakoor Z, Antenatal screening for syphilis at a tertiary care hospital in Riyadh, Ann Saudi Med, 2004; 24(4): 262-264.

[15] Hossain A, Serological tests for syphilis in Saudi Arabia, Genitourin Med, 1986; 62(5): 293-297.

[16] Zimmo SK, Riad HMA, Ramadani HM, Al Sebiani SA, Seroprevalence of sexually transmitted diseases among pregnants in Jeddah, Egypt J Derm Androl, 2000; 20(2): 71-76.

[17] [No authors listed], Maternal and Perinatal Infection: Report of WHO Consultation. Geneva: World Health Organization. 1991: 29.

[18] [No authors listed], 1993 sexually transmitted disease treatment guidelines. Centers for Disease Control and Prevention, MMWR Recomm Rep, 1993; 42(RR-14): 1-102.

[19] Kiss H, Widhalm A, Geusau A, Husslein P, Universal antenatal screening for syphilis: is it still justified economically? A 10-year retrospective analysis, Eur J Obstet Gynecol, Reprod Biol, 2004; 112(1): 24-28. 
تحري الزهري قبل الولادة: هل تز ال هناللك أهمية للفحص

الثامل فى المملكة العربية السعودية ؟

\section{شريفة علي الصبياني}

قسم النساء والولادة، كلية الطب، جامعة الدلك عبدالعزيز

جلة - المدلكة العربية السعودية

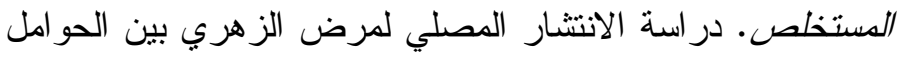

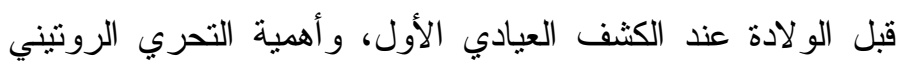

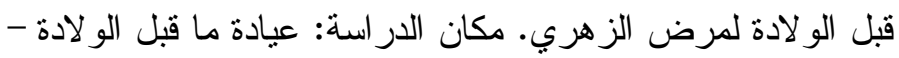

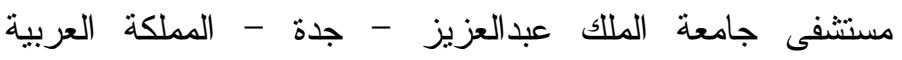
السعودية. عن طريق عمل نحليل استعادي لنتائج النحليل القبل

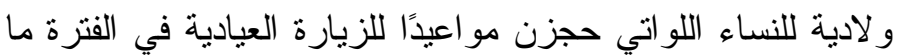

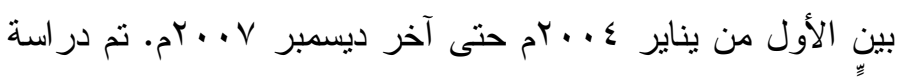

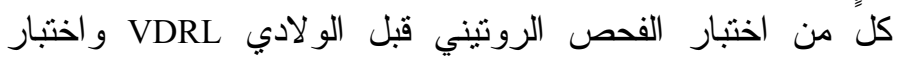

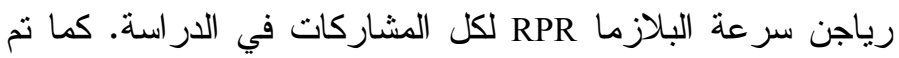

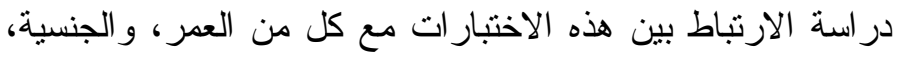

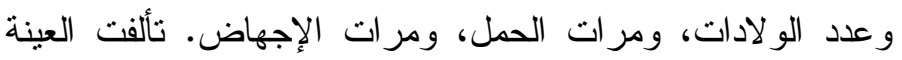

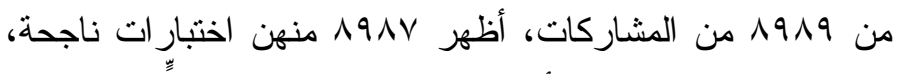

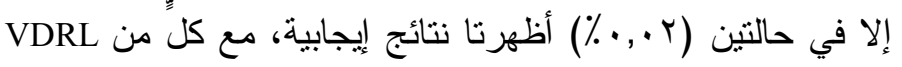

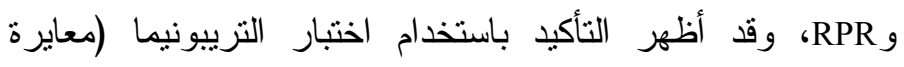

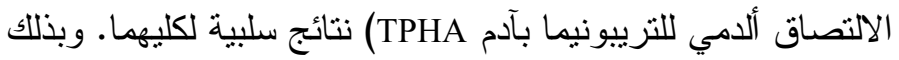

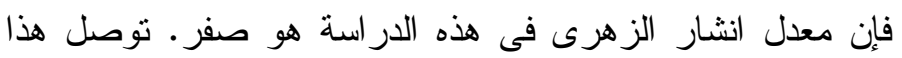

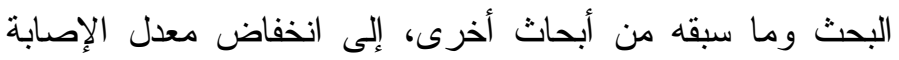

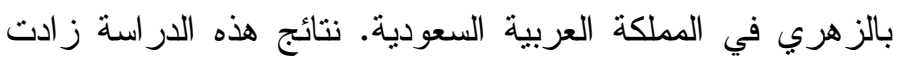

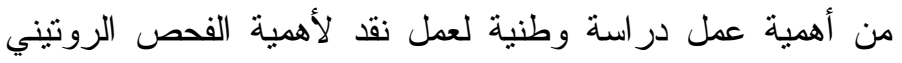
الثامل لمرض الزهري قبل الو لادة في المملكة العربية السعودية. 